\title{
De-romanticising dialogue in collaborative health care research: a critical, reflexive approach to tensions in an action research project's initial phase
}

\author{
Louise Phillips, ${ }^{1}$ Birgitte Ravn Olesen, ${ }^{1}$ Michael Scheffmann-Petersen, ${ }^{1}$ Helle Merete Nordentoft ${ }^{2}$ \\ ${ }^{1}$ Department of Communication and Arts, Roskilde University; ${ }^{2}$ Department of Education, Aarhus University, Denmark
}

\begin{abstract}
In the current socio-political conjuncture, collaborative, dialogic forms of knowledge production abound and are idealised as democratic and inclusive. The aim of the article is to contribute to the body of critical, reflexive analyses of collaborative research by analysing how complex dynamics of exclusion as well as inclusion create tensions in researchers' attempts to establish collaborative relations in the initial phase of an action research project. The analysis applies a framework combining Bakhtinian dialogic communication theory and Foucauldian theory to explore inclusion and exclusion in the tensional interplay of multiple voices whereby certain voices dominate. Finally, the article offers a typology of ideal types of collaborative research relations that can be used in the initial research phase as a platform for reflexive discussion between researchers and potential collaborative partners about their respective understandings of collaboration and dialogue and corresponding expectations about the research process and results.
\end{abstract}

\section{Introduction}

Across diverse disciplines and empirical contexts globally, collaborative research practices abound. In collaborative research, social actors in the fields under study are invited to participate as co-researchers together with university researchers in the co-production of knowledge across multiple, academic and non-academic knowledges.

Correspondence: Louise Phillips, Department of Communication and Arts, Roskilde University, Denmark Universitetsvej 1, Roskilde, Denmark.

Tel.: 4076.3799.

E-mail: louisep@ruc.dk

Key words: Bakhtinian dialogic communication theory; Collaborative research; Democratic methodologies; Dialogue; Initial phase of action research.

Contributions: the order in which the authors appear in the byline reflects their relative contributions to the article.

Conflict of interest: the authors declare no potential conflict of interest.

Funding: none.

Received for publication: 7 November 2017.

Revision received: 12 February 2018.

Accepted for publication: 24 February 2018.

This work is licensed under a Creative Commons Attribution NonCommercial 4.0 License (CC BY-NC 4.0).

(C) Copyright L. Phillips et al., 2018

Licensee PAGEPress, Italy

Qualitative Research in Medicine \& Healthcare 2018; 2:1-13

doi:10.4081/qrmh.2018.7178
Of course, collaborative knowledge production has a long history in the tradition of action research with its ideals of democratising relations between researchers and researched and transforming practices through processes of mutual learning. ${ }^{1}$ The current wave of collaborative research extends beyond the bounds of action research to cover not only action research but also a multiplicity of other heterogeneous research practices in relation to a myriad of different fields including social and health care. ${ }^{2-6}$ Edwards and Brannelly (2017) suggest that these heterogeneous research practices are based on linked but distinct methodologies that include, but are not restricted to, inclusive methodologies, co-production methodologies, decolonising/ indigenous methodologies and feminist ethics of care methodologies.

The burgeoning of collaborative research can be understood as part of the so-called dialogic turn, a societal tendency in which collaborative practices have proliferated across diverse social fields as a means of generating new knowledge with a view to practice change..$^{7-9}$ According to dialogic ideals, expert knowledge is democratized in the dialogic turn as the authorized knowledge of mainstream research loses its monopoly on truth, multiple ways of knowing (including experiential, embodied knowledges) are recognised as legitimate knowledge forms, and multiple actors are acknowledged as kinds of expert (including experience-based experts). ${ }^{9}, 10$ In addition to various types of collaborative research, other practices in the dialogic turn include the co-production of health and social care, inquirybased learning in education, public engagement with science and the environment, collaborative therapy, and bottom-up organisational change. Dialogue and collaboration have become buzzwords with a taken-for-granted positive value. The assumption is that, by harnessing difference 
as a transformative force, dialogue can generate new knowledge across differences, including differences of organizational position and professional background, theoretical perspective, age, gender, ethnicity and social class. ${ }^{11-13}$ Participants, it is claimed, are empowered as co-learners, coresearchers or dialogue partners as opposed to clients, patients, informants, target groups or consumers. Exponents assert that, as long as dialogic principles and methods are followed, then dialogue and collaboration will fulfill the promise of democratic, participatory processes. ${ }^{14-16}$

\section{Beyond the buzzwords}

The current socio-political conjuncture appears, at first glance to be highly supportive of, and conducive to, collaborative research based on inclusive, democratic, dialogic principles. In this article, we go beyond the buzzwords by challenging this idealised picture on two counts. First, we assert that research conditions in the current conjuncture hinder and circumscribe - as well as enable and nurture - collaborative forms of research. Second, we aim to de-romanticize dialogue and argue that collaborative research encompasses not only inclusion but also exclusion arising from the intrinsic complexities of dialogue. In the article, we explore how collaborative research, including collaborative health care research, is riddled with tensions stemming from dynamics of exclusion and inclusion in complex processes of dialogue. We do this through critical, reflexive analysis of the initial phase of a collaborative study of health care in which the four of us co-authors made up a team of university researchers. A key analytical point is that one of the main voices in the initial phase romanticizes dialogue as an inclusive, straightforward process, rendering it difficult for participants to detect dynamics of exclusion. The aim of the collaborative research project with respect to practice was to generate knowledge and practice innovations that would strengthen collaboration between primary and secondary health care sectors and across professions in person-centered rehabilitation for older people with cognitive impairment so that a greater number of older people with cognitive impairment and their relatives experience smooth and coherent processes of rehabilitation in which they feel empowered as dialogue partners and agents in collaborative decision-making. The aim with respect to research was to contribute to the research field on crosssectoral and inter-professional collaboration in personcentered social and health care (including care for older people) and to the broader research field on the dialogic turn. The collaborative research design was based on the participation of older people with cognitive impairment, their relatives and social and health care practitioners as co-researchers in the co-creation of knowledge and practice innovations in a series of workshops. The initial phase consisted of the following elements: a response to a call for applications by a funding body; attempts over a sixweek period to establish relations with actors in the field
- including the consultant doctor in a geriatric ward and three teams of dementia specialists - with a view to recruiting them as co-researchers; the formulation of a project description; the writing and submission of an application to the funding body; and the consideration of the submitted application by the funding body. Tensions stemming from dynamics of inclusion and exclusion in the making of the project were its unmaking as they led to the breakdown of relations with potential co-researchers. Key co-researchers dropped out the day before the deadline for the application, leaving the project bereft of the mutual commitment to collaboration between actors in the field of practice and the university research team that the call for applications, and our own dialogic research principles, stipulated. The rejection email from the funding body came as no surprise.

As an analytical framework, we use the Integrated Framework for Analysing Dialogic Knowledge Production and Communication (IFADIA) ${ }^{8}$ that builds on Bakhtin's theory of dialogue. ${ }^{17-19}$ and Foucault's theory of discourse and power/knowledge. ${ }^{20-22}$ Within this framework, dynamics of inclusion and exclusion are conceptualized in terms of the tensional interplay of multiple voices whereby certain voices - discourses constructing particular forms of knowledge and subjectivities - dominate and others are marginalised. The analysis highlights tensions emanating from the ways in which dialogue in collaborative research relations is ascribed meaning and enacted in the interplay between, on the one hand, a voice that democratizes research and sometimes romanticizes dialogue and, on the other, a sovereign researcher voice maintaining strict boundaries between the researcher and researched. The buzzword status of dialogue, collaboration and related terms articulated in the romantic voice of dialogue was itself performative in masking the tensions in play: since the buzzwords have an unquestionably positive status, it was difficult to reflect critically on the complexities of practices constructed in their terms. As a result, when we articulated the romantic voice, we reproduced an idealized view of dialogue despite our theorisation of dialogue as complex and tension-ridden.

The material for analysis is our own narrative account of the initial phase of the project. By exploring the tensions in researchers' attempts to establish collaborative relations in the first phase of a collaborative research project on health care, the article aims to contribute to the body of critical, reflexive analyses which de-romanticize dialogue and critically interrogate the play of power in collaborative research and teaching practices ${ }^{2,4,8,23-26}$ as well as in other practices in the dialogic turn such as communication for social change $\mathrm{e}^{27,28}$ and public engagement with science and technology. ${ }^{29-32}$

Within this body of critical research, studies have identified obstacles to mutually fruitful collaborative research, arising, variously, from the roots of the academic researcher and the practitioner co-researchers in different 
social worlds and cultures, from power differences, from adherence to different understandings of what counts as knowledge, and from different expectations as to the research outcome. ${ }^{33-38}$ There is a relatively small amount of literature on the tensions in the preliminary phase of collaborative research. Gayá Wicks and Reason ${ }^{39}$ (p. 243) point out that the beginning of the research process is crucial for its success or failure, and they review key challenges, paradoxes and opportunities arising in the preliminary phase of action research. Kumsa et al. ${ }^{40}(\mathrm{p}$. 420 ) argue that it was particularly important to explore the first stage of their participatory research as $[t]$ his was where the intensities of inequitable relations of power were manifest. Cook ${ }^{41}$ and Kristiansen and BlochPoulsen ${ }^{42}$ have written about the challenges of initiating action research that has originated in applications penned by the university researchers alone, reflecting on the paradox that top-down decision-making about the research design was the starting-point for the bottom-up, democratic co-production of knowledge. There is no literature of which we are aware on the phase in which university researchers, in the process of putting together a research application for funding, explore the possibilities for research with potential collaborative partners. Filling this gap, our analysis of this phase highlights both the crucial importance and the immense difficulty of establishing relations of mutual trust amongst the participants in collaborative research. It attributes that difficulty to the messy, tensional complexity of dialogue.

First we present the material for analysis, a narrative account entitled Our Story: Another one bites the dust! which we, the four co-authors of this article, have written together about the initial phase of the project. Then we sketch out our theoretical framework, the Integrated Framework for Analysing Dialogic Knowledge Production and Communication and analytical foci. Following this, we apply IFADIA in analysis of the narrative, focusing on tensions that arose in key dialogic relations in the initial phase. In the discussion and conclusion, we offer a typology of ideal types of collaborative research relations. We illustrate how the typology can be used in the initial phase as a platform for critical, reflexive discussion between researchers and their potential collaborative partners about their respective understandings of collaboration and dialogue and the implications of those understandings for expectations with respect to the research process and results.

\section{Using a narrative account to unfold the tensions across multiple voices}

The process of creating the narrative account for analysis (below) began with one of us presenting a paper at a conference two months after receiving the rejection letter from the funding body. In her conference paper, she wrote a narrative to recount her personal experiences of the difficulties of gaining funding for collaborative, dia- logic research. After the conference, we used this narrative as a basis for collectively exploring our experiences of the initial phase of the project and, through this process, we wrote the joint narrative.

We chose the narrative as the material for analysis on the grounds that the narrative genre draws attention to itself as a narrative, a contingent, situated representation of reality offering partial truths. ${ }^{43,44}$ This, we believe, is fitting given our intention for analysis of the material to serve as a contribution to discussion about the centrality of establishing collaborative relations in action research and the messy, tensional complexity of dialogue in those relations. Stories hold a dialogic potential due to their capacity to keep several viewpoints simultaneously in play. ${ }^{17,43,45}$

We recognize that we (re)present ourselves in the narrative account through a singular we which papers over internal tensions and differences; at the same time, sticking to this singular we allows us to keep the complexities within manageable bounds given the page limits for this article. The narrative genre allows us to represent and analyze, first, how a story can contain multiple voices and, second, how these voices - discourses constructing knowledge and subjectivities - collide and clash as they merge with and/or contest each other.

\section{Our story: Another one bites the dust!}

\section{Right up our street}

This story is entitled 'Another one bites the dust!' As this title indicates, the story doesn't end well! But it started off well. With an application to a private funding body's call for collaborative research based on close cooperation between university researchers in the humanities and social sciences and people in the field under study. The funding body's call was tailor-made for the research we carry out in our centre for dialogic communication; in our centre, close collaboration with the field under study is alfa and omega. We do 'research with' rather than 'research on' and we pride ourselves on research in which 'dialogue' is, at one and the same time, the object of study and a methodological principle. Thus we strive to study 'dialogue' dialogically through a collaborative research design and with the use of methods for facilitating dialogue. So we followed this model in formulating the collective research project design for our application to the funding body. In treating 'dialogue' as methodological principle, the research would be based on a collaborative design in which actors in the field of study would participate as coresearchers, dialogic ethical principles would be followed, and methods would be used for facilitating dialogue in fora for the co-creation of knowledge and practice innovations.

The topic was cross-sectoral and inter-professional collaboration in rehabilitation for older people with cognitive impairment, and it aimed both to contribute to practice and to research. The aim with respect to practice was to gener- 
ate knowledge and practice innovations that strengthen collaboration across sectors and professions so that a greater number of older citizens with cognitive impairment and their relatives experience smooth and coherent processes of rehabilitation in which they feel involved and empowered as dialogue partners and agents in collaborative decisionmaking. The aim with respect to research was to contribute to the research field on cross-sectoral and inter-professional collaboration in person-centered social and health care (including care for older people) and to the broader research field on 'the dialogic turn'.

We formulated the practice aim and more specific goals - and also the research design to realize that aim and those goals - on the basis of dialogue with practitioners.

\section{Dialogue with practitioners}

We met two groups of practitioners in two different settings - a municipal community health team and a crosssectoral health team. In dialogue with practitioners, we presented our critical, reflexive take on the potentials and tensions of dialogue. 'Collaboration is a good thing', we said, 'because, in collaborative practices, we co-create knowledge in dialogue by harnessing difference as a generative force'. And then we went on to say that 'collaboration' and 'dialogue' and 'co-creation' have become policy buzzwords with a taken for granted positive value blinding us to the tensions which stem from power dynamics in which certain knowledge forms dominate and others are marginalised or excluded'. And then we asked 'Do you experience problems when you collaborate that you would like to be tackled through practice-oriented research?'.

The practitioners on the frontline of cross-sectoral collaboration and patient-centered care in everyday work practices were enthusiastic as what we said resonated with their understandings of their work practices and the conditions shaping them. They nodded when we said that dialogue had become a buzzword, and they nodded again when we pointed out that dialogue was fraught with tensions that had to do with power relations. And when we asked them to tell us about the problems that they would like to be tackled, they fluently elaborated on a number of problems they faced in their daily work. We said that we would like to tackle those problems with them in collaborative research in which they were co-researchers and, together, we would co-create knowledge in the meeting between our research-based knowledge and their expertise rooted in their everyday work practices and professional knowledge. They replied that they would like to very much. Because they wanted to solve the problems and because they appreciated that those problems were complex and could best be tackled bottom-up by opening up to multiple voices, including their own; they were tired of management imposing top-down changes without taking their expertise into account.

The hospital consultant (doctor) was also initially very positive. She appreciated what we said about the promise and complexities of dialogue and she rapidly reeled off a list of problems she experienced in cross-sectoral collaboration. She liked the fact that the project would fully compensate financially for the time that staff would spend as co-researchers in dialogue workshops since the department was strapped for resources. Without hesitation, she committed herself and her team to the project (obviously pending approval by upper management). At the same time, she told us that she was very busy and that it would suit her best if she first became actively involved if the application was successful. We assured her that that was fine with us and that we would do the work of writing the application but that we would send it to her for comments to ensure that our representation of cross-sectoral practices was accurate and the research design in line with her knowledge of the field of practice.

\section{From agreement to skepticism}

After about 10 days, we sent her a three-page Danish language research design to which she sent us comments, all at a rather micro level and within the terms of our project. It took a couple of weeks before we sent her a full draft of the application in English as it took us a long time to meet other partners and to gain a sufficient understanding of the field of practice. It took so long because the field was extremely complex and characterized by huge ongoing structural changes, which meant that not even practitioners had an overview of the field's complex network of relations. By the time we sent the English language draft, her unhesitant support had shifted to ambivalence. On the one hand, she still liked the practice-oriented nature of our research - that we didn't just want to contribute to a research field but also wanted to further practice change that would make a positive difference for her workplace, patients and staff. On the other hand, the research design now seemed to clash with her professional and scientific principles. She was skeptical about the ethics of vulnerable, cognitively impaired patients participating as co-researchers; she was unsure about what research-based knowledge we would be contributing; what we called research didn't resonate with her existing understanding of research where researchers have the monopoly on truth and there are clear lines of demarcation between researchers and researched. Her new skepticism surprised us. The earlier Danish language research design outline had not seemed to clash with her principles. We wondered if the draft's English language (a requirement of the funding body) made it harder to relate to. We contacted her and she told us that it was a colleague in the other sector who had sowed doubt in her mind about the project.

\section{Rejection}

The colleague who had sowed the doubt was an expractitioner who was now a consultant responsible for development projects designed to improve practice. We had 
had a meeting with her and she had been negative from the beginning. Why that was the case, we can only speculate. We speculate that it may have had something to do with the complex politics of the social and health care system, the blurring of the boundaries between researchers and researched that our collaborative project entailed, and the development consultant's position as responsible for projects for developing practice. Our project offered both research and development, and therefore may have been experienced as invading her territory. While all the other actors had appreciated our bottom-up approach, when we asked her what the problems were, she responded as if she took our question to reflect insecurity and ignorance rather than a commitment to democratic, bottom-up knowledge production. 'You are the experts, it's your job to know the answers, why are you asking me?'.

Whatever the reason, the development consultant rejected our project on behalf of the team of practitioners with which she did development work and sowed the seeds of doubt with the hospital doctor who withdrew her commitment and that of her team the day before the deadline for the application. With the teams with which they collaborate across sectors no longer participating, the two groups of practitioners who had committed themselves enthusiastically to the project were forced to withdraw. A very good example of the domino effect!

\section{Poor us}

We handed in an application bereft of key collaborating partners, knowing all too well that it was doomed to rejection given that the call was for practice-oriented research based on close cooperation between researchers and actors in the field under study. Six months later, we received the news we had expected. Our application had been unsuccessful principally because of the absence of key collaborating partners. We were informed by a representative of the funding body that it was a very highquality application that had been given an excellent evaluation by both the researcher-reviewer and the practitioner-reviewer. In particular, the researcher-reviewer praised the integration of theory and practice and the use of dialogic research principles, theories and methods in order to study dialogue and contribute to both research and practice.

At the same time, we were also told that we probably would not have been awarded the grant even if our collaborating partners had not withdrawn. This was because the practitioner-reviewer had criticized the absence in our research design of general practitioners as co-researchers. We pointed out that it is well-known that it is rare for general practitioners in Denmark to participate as co-researchers. We also pointed out that it was, in general, much more difficult to establish research collaborations in which collaborating partners participate as co-researchers. Especially because co-researchers have to invest significant time (and other resources) compared to practitioners being observed or interviewed in non-collaborative qualitative research relations. And we asked if they ever gave grants to action research or similarly collaborative projects such as ours. Her reply was yes, they did. So we read the descriptions of funded qualitative research projects on the funding body's website, searching for projects that used collaborative methods as well as ethnographic ones (our project would have used both). We found none! There was no sign that any of the funded projects invited their collaborating partners and/or actors in the field to participate as participants in the co-creation of knowledge; the boundaries of researcher and researched were not breached.

\section{Theoretical framework}

From dialogic communication theory, our theoretical framework, the Integrated Framework for the Analysis of Dialogic Knowledge Production (IFADIA), incorporates Bakhtin's conceptualization of dialogue as relational meaning-making whereby meaning is formed across multiple - and often contradictory and opposing - voices; meaning-making, then, is multi-voiced or polyphonic. ${ }^{17}$ In polyphonic meaning-making, a struggle takes place between centrifugal and centripetal tendencies towards, respectively, difference and unity. In Bakhtin's understanding, voices are not just the media for speech or the uttered speech of embodied persons but also discourses, ideologies, perspectives or themes. ${ }^{17,18}$ Meaningmaking is tensional and dialogic as it is produced through the polyphonic play of multiple voices, and a person can articulate many voices, including contradictory ones constructing competing knowledges and identities. IFADIA goes much further down a poststructuralist path than dialogic communication theory in drawing on Foucault's theory of discourse and power/knowledge which asserts that our knowledge of the world, including our experience of self and others, is constructed in historically contingent discourses which exclude or marginalize other ways of being, knowing and doing. ${ }^{20-22}$ This poststructuralist development of dialogic communication theory is at the core of IFADIA's analytical lens.

Although dialogue is linked to power in most dialogic communication theories, the linkage is often left largely unexplored..$^{46}$ By adding Foucault's theory of discourse and power/knowledge, IFADIA becomes analytically equipped for, and oriented towards, exploration of the ways in which the inevitable operation of power/knowledge works, through the articulation of discourses in the context-specific enactment of dialogue, to enable, and set the boundaries for, the action of all participants. This underpins an empirical focus on how the discourse of dialogue itself constitutes a form of governance in which knowledge, power and subjectivities are constructed in particular ways that marginalise or exclude other ways of being, knowing and doing. ${ }^{20-22}$ IFADIA contains a call for 
reflexivity about the inevitable operation of dynamics of inclusion and exclusion, and advocates reflexive analysis building on empirical, context- and complexity-sensitive study of the tensions in dialogue and collaboration. It follows a critical, Foucauldian approach that interrogates the play of power/knowledge in the articulation of dialogue, but, at the same time, it treats critique as the basis for reflexive considerations that can lead to the further development of dialogic practices from a position normatively supportive of the dialogic turn. ${ }^{8}$

The intention is that critical reflexivity about the production of power/knowledge in the discourse of dialogue can form a platform for a destabilisation of discourse that can open up for practice change in a particular, normatively prescribed, direction. It is not meant as a basis for eradicating exclusion; according to the Foucauldian perspective, a dominance-free zone for equal relations is an impossibility and the dominance of certain voices over others is not only inevitable but not necessarily a problem. We are also aware that - from our post-structuralist position that all knowledges are contingent representations of reality - our stance on critique and the concepts we use are discursively constructed from a particular perspective that excludes and marginalizes other perspectives.

We are well aware that we are violating dialogic ethical principles in our narrative by using reported speech which paraphrases others' words and by making speculations about the motivations and reactions of others. Furthermore, we know that objectification of the other is inherent in telling others' stories for them. As Letiche puts it, representation steals the other's voice and imposes the author's point of view so that $[t]$ he writer is ethically implicated in her (his) inability to do (complete) justice to the other within any episteme of representation ${ }^{47}$ (p. 274). We can never eliminate objectification even with deliberately multi-voiced texts. However, we believe that we can work with techniques of representation that cultivate the performativity of texts - that texts are positioned in, and act on, the world - and are reflexive about the researcher's positioning of herself and others and create spaces for multiple voices, understood as discourses constructing knowledges and subjectivities. ${ }^{48-50}$

Selves, for Bakhtin, are multi-voiced as they are constituted through the interplay of multiple voices in the negotiation of meaning in dialogue. In contrast to a phenomenological understanding of dialogue as authentic communication based on experience of direct unmediated contact with others ${ }^{51}$ (p. 138), a Bakhtinian approach asserts that all human life is inherently dialogic, and everyday life is saturated with dialogical tensions. ${ }^{8,11}$ The tensions are intrinsic to struggles between centripetal and centrifugal forces since voices - discourses articulating multiple meanings - are locked in a constant tug-of-war in which some voices dominate over others. Applying IFADIA as a theoretical framework entails an analytical focus on these ten- sions. Our analysis of the narrative account of the initial phase of the collaborative research project homes in on the ways in which our interaction with potential collaborating partners opened up for dialogue across a polyphonic plurality of voices but also excluded voices and thus privileged certain ways of knowing and marginalised others. Our analysis using IFADIA addresses the following empirical questions: i) What voices - discourses constructing specific knowledges and subjectivities - are articulated in the attempted establishment of collaborative research relations and when and how are they articulated and heard?; ii) To what extent, when, and how, do the interactions among actors open up for the polyphonic articulation of multiple voices that construct plural forms of knowledge?; iii) To what extent, when, and how do the interactions circumscribe the opening up for different voices, and, along monological lines, construct a singular we and a singular form of knowledge?

\section{Analysis of the tensions in the enactment of dialogue}

Tensions arose in the interplay between top-down and bottom-up dynamics in the following dialogic relations: relations between our research profile and the funding body and, in particular, the Call for Applications text, ${ }^{1}$ relations with potential co-researchers; relations with health care managers who were gatekeepers with respect to recruiting co-researchers; and relations with general practitioners. We deal with each in turn.

\section{Relations with the funding body}

In the Call for Applications, the funding body invited proposals for research in which university researchers and actors in the field under study engage in equal collaboration with a view to contributing both to research and to practice change. Our research fitted this call perfectly, as we noted in the first section of our narrative, entitled Right up our street.

The first section of the narrative includes a commitment to studying dialogue dialogically through a collaborative design in which actors in the field of study would participate as co-researchers but it also outlines the type of theory (a combination of dialogic communication theory and poststructuralist theory on power/knowledge) and the analytical focus (critical, empirical analysis of how new knowledge is created collaboratively through dialogic communication and the tensions at work through $d y$ namics of both inclusion and exclusion). There is a clash here between our adherence to dialogic research principles, on the one hand, and, on the other hand, our identification of theory and analytical focus prior to approaching potential research partners. This clash can be understood as a tension between two competing voices. Adherence to dialogic research principles involves the ar- 
ticulation of the voice of democratic researcher who relinquishes her monopoly on truth and engages in co-research with co-researchers; in contrast, the identification of theory and analytical focus solely by the university researchers invokes the conventional, sovereign researcher voice in complete control of the research process.

This tension between the voices of democratic researcher and sovereign researcher is also in play in the Call for Applications:

[The funding body] will, therefore, centring on research in the humanities, further equal collaboration between researchers and actors within the social, ageing or environmental areas which are all important areas for funding in the funding body's daily practice [...]

The project will embrace both university researchers in the humanities (see next point), perhaps other relevant researchers from other research institutions, and actors from fields of practice in tightly integrated collaborative relations in the different parts of the project.

The part of the research that is in the humanities will be carried out by university researchers from the universities (...) and disciplines belonging to the areas covered by the funding body [...]

The research part must not only consist of applied research, data collection or evaluation reports but must also contain research aims and results that are grounded in pure research in the humanities. The practice part with its focus on development must be methodologically innovative, focus on the documentation of effects and preferably include practice collaborations across professions and sectors. In addition, it must be possible for the practical consequences of the project to be sustained and to be economically sustainable.

The democratic researcher voice - in which research is a joint action where university researchers and actors in the field collaborate - is articulated in the requirement that the project must include both university researchers and actors in the practice field in equal collaboration and tightly integrated collaborative relations. However, the authoritative researcher voice dominates through the sharp division of labour whereby the university researchers have sole responsibility for research: The part of the research that is in the humanities will be carried out by university researchers from the universities (...) and disciplines belonging to the areas covered by the funding body. Thus the Call constructs an understanding of collaboration that maintains clear boundaries between the researchers and the researched. Moreover, in line with the norm for funding body applications, the application is expected to map out a clearly delineated research design covering the choice of theory and method to results and impact. While the call for applications stipulates a collaborative design, it also requires a detailed outline of the research plan:
The project's aims and content with respect to research and practice: the project's relations to current research, practice and challenges in the area (scientific and societal relevance); the project's target group; the project's activities and methods; the project's organisation, organisational anchoring and support including the organisation of collaboration between research and practice; the time-frame, course of events and expected results for the research part, the practice part and the involved citizens.

The question is whether it would be at all realistic within the tight time-frame of six weeks between the announcement of the call and the deadline for applications - to be able to engage in negotiations with potential research partners about the basic theoretical and analytical underpinnings of the project in order to co-produce a detailed outline of the research plan. Moreover, we considered it completely infeasible to establish relations and negotiate with potential co-researchers central to the research design - patients and relatives - given that they would be recruited by the professionals only if the project went ahead. This is particularly paradoxical given that the aim of the research was to empower older people with cognitive impairment (patients) and their relatives as dialogue partners in collaborative decision-making in the rehabilitation process. The infeasibility of the participation of patients and relatives in the proposal phase - and also their almost total absence in our narrative account (we only refer to the hospital doctor's expression of concern about patients' ability to participate as co-researchers) - demonstrates the chasm of power between patients and relatives, on the one hand, and academic researchers and social and health care practitioners, on the other. In the narrative section, Poor us, we claim that it is much harder and more time-consuming to establish relations in which collaborating partners are engaged as coresearchers than to establish relations in non-collaborative qualitative research in which clear boundaries are maintained between the researcher and researched. The narrative describes how the funding body representative is asked if there are collaborative projects among the funded projects and her answer is yes. It is also noted in the narrative that we would categorize the funded projects as qualitative ethnographically-oriented research rather than collaborative research.

All this could be read as if we do not think it is possible for collaborative research projects to be awarded funding. But, actually, we do! We know that collaborative research does get funded in Denmark and several of the collaborative research projects in our own research centre have been funded by external funding sources. However, often there is either pressure from fields of practice to carry out research completely on their premises or the researchers carry out the research primarily on their own premises, maintaining clear boundaries with the researched while still labelling the researched co-researchers and the research 
action research or collaborative research. Pressure from fields of practice may lead to an emphasis on practice development and the reproduction of normatively anchored trajectories based on the status quo in the practice field to the detriment of critical research which could challenge taken-for-granted meanings and disrupt the status quo. ${ }^{52} \mathrm{An}$ anchoring of the research in researchers' own premises may in contrast, lead to aims and results that contribute to the research field but not to practice change.

\section{Relations with potential co-researchers}

The section of the narrative entitled Dialogue with practitioners described how we presented our approach to dialogue and collaboration in our meetings with potential partners as follows:

Collaboration' is a good thing, we said, 'because, in collaborative practices, we co-create knowledge in dialogue by harnessing difference as a generative force'. And then we went on to say that 'collaboration and dialogue and co-creation have become policy buzzwords with a taken for granted positive value blinding us to the tensions which stem from power dynamics in which certain knowledge forms dominate and others are marginalised or excluded'.

Here, we position ourselves as actors with an analytical, critical distance to the practices that we analyse and a critical, reflexive take on our own practice as exponents of collaboration as a good thing. We did not open this framework up for discussion along dialogic lines! We adopted a dialogic approach only after this, articulating the democratic researcher voice by inviting - along bottom-up lines - their experience-based knowledge on problems arising in collaboration that they would like to be tackled through practice-oriented research: And then we asked 'Do you experience problems when you collaborate that you would like to be tackled through practice-oriented research?'. At the same time, we do not position them as co-researchers in the process but as providers of knowledge about a problem which they would like to be tackled through research. Thus the democratic researcher voice is merged with a consumerist voice placing actors in the field not as co-researchers but at the receiving-end of a service: they are positioned as consumers, and research is construed as a service to be supplied to fit their consumer needs; to identify those consumer needs, we position them as informants representing the target group of the research service we will supply.

The positioning as consumer-informants continues in the next piece of narrative where the team members are positioned as compliant informant-consumers responding positively to our declarations of our standpoint and request: they nodded when we said [...] and they nodded again when we pointed out and when we asked them to tell us [...] they fluently elaborated. We then describe their acceptance of our offer to tackle the problems together with them in collaborative research as a smooth, uncomplicated process: We said that we would like to (...) co-create knowledge in the meeting between our research-based knowledge and their expertise rooted in their everyday work practices and professional knowledge. They replied that they would like to very much. Because they wanted to solve the problems and (...) they were tired of management imposing top-down changes without taking their expertise into account. Here, we presume to know with certainty their cognitive and emotional grounds for accepting the offer; instead of clearly demarcating their utterances from ours, their voices are fully subsumed in ours and, in Bakhtin's terms, we finalize them instead of recognizing that selves are unfinalisable since they are formed and reformed through the continuous negotiation of meanings across multiple voices. ${ }^{43}$

\section{Relations with health care managers}

In the part of the narrative about relations with health care managers, there is a clearly formulated division of labour between the hospital consultant and us - whereby the hospital consultant would only become actively involved if the application was successful and we would do the work of writing the application. This agreement does not invoke the equal collaboration of the Call for Applications or the notion of co-research integral to our espoused approach to studying dialogue dialogically. But, at the same time, the sovereign researcher voice with its monopoly on truth is not reproduced uncontested. Rather, there is a tension between the sovereign researcher voice and a democratic researcher voice which recognizes multiple knowers as experts. On the one hand, we invoke the sovereign researcher voice in positioning ourselves as having the sufficient time and knowledge to be able to take charge of the writing process. On the other hand, we invoke the democratic researcher voice in positioning the hospital consultant as provider of information about practice and in opening up for practice-based expert knowledge. However, the consequence of our taking control of the writing process is that the sovereign researcher voice takes over the design of the project - its metatheory, theory and methodology - as the design is carefully mapped out in the application without the inclusion of, or negotiation with, alternative theoretical or methodological perspectives. As provider of information about practice, the hospital consultant is positioned as an expert but only with respect to practice and hence not on equal terms as partners in co-research with us university researchers.

The dominance of the sovereign researcher voice is not acknowledged in our narrative. We write in the first section of the narrative: We formulated the practice aim and more specific goals - and also the research design to realize that aim and those goals - on the basis of dialogue with practitioners. The sovereign researcher voice is articulated here without reflexivity. We, the university researchers, are the we who are the main agents of the action of formulating the practice aims, more specific goals, and 
the research design; our potential partners are objects with a supporting role as practitioners in which we engage in dialogue. Moreover, there is no recognition that, although we attempted to incorporate perspectives presented in our dialogue with practitioners, our taking charge of the writing process necessarily circumscribed the articulation of those perspectives and, therefore, marginalized practitioner voices.

In the section of the narrative named From agreement to skepticism, we speculate as to why the hospital consultant is skeptical: the research design now seemed to clash with her professional and scientific principles. She was skeptical about the ethics of vulnerable, cognitively impaired patients participating as co-researchers. We interpret her skepticism as an expression of professional and scientific principles instead of listening to her concerns as legitimate questioning rooted in her professional expertise. The hospital consultant becomes the different Other without a legitimate voice, and in the narrative we merely wonder if the draft's English language (...) made it harder to relate to.

In the section of the narrative named Rejection, we interpret a conflict between us and a development consultant who acted as gatekeeper for a health care team as the development consultant's rejection of our invitation to engage in bottom-up knowledge production. We describe how we experienced her response to our questions about how she experienced problems in the field: she responded as if she took our question to reflect insecurity and ignorance rather than a commitment to democratic, bottomup knowledge production. 'You're the experts; it's your job to know the answers, why are you asking me?'.

According to the interpretation we put forward in the narrative, then, the development consultant articulates the sovereign researcher voice which establishes a strict boundary between the researcher and researched; for her, expert authority with respect to research rests exclusively with the researcher.

\section{Relations with general practitioners}

In the narrative section Poor us, it is mentioned that we were informed by the funding body representative that, even if no collaborating partners had withdrawn, the project probably would not have been funded because we had not involved general practitioners in the project design. We note our reaction to this information: We pointed out that it is well-known that it is rare for general practitioners would participate as co-researchers. In Denmark, general practitioners have private practices under contract with, and funded by, the public sector. In comparison with the other actors in the project, including the researchers, they have high incomes and a strong trade union. This means that it is generally very difficult to engage general practitioners not only in collaborative research but also in conventional research as informants in interviews. This situation is widely recognized in research circles.

\section{Discussion}

We have aimed in this article to contribute to the field of collaborative health care research - and collaborative research in general - by de-romanticising dialogue and arguing for a critical, reflexive approach based on the theoretical framework, IFADIA, a combination of Bakhtinian dialogic communication theory and Foucauldian theory of discourse and power/knowledge. Illustrating this approach, our analysis of a narrative account of the initial phase of a collaborative health care research project interrogated the tensions in struggles between multiple voices - discourses articulating different knowledges and subjectivities - enmeshed in a tug-of-war in which some voices dominate and others are marginalised.

Although IFADIA theorises dialogue in terms of complex, tensional dynamics of inclusion and exclusion whereby certain voices dominate and others are marginalised, our analysis of the narrative shows that, in writing the narrative, we were not reflexive about how discourses ascribe contingent meanings to terms, excluding and marginalizing alternative ways of knowing. When writing this article, we - as co-authors - have discussed how we can talk about collaboration and dialogue in ways that acknowledge and explore the different meanings which different discourses ascribe to the terms and the implications these differences have for collaborative research relations. On the basis of our analysis of the narrative, we have constructed a typology of different ideal types of collaboration (Figure 1). The typology suggests that most forms of collaborative research articulate one or more of the four ideal typical positions depicted in Figure 1 and described below. The typology is not intended as a fixed standard or onesize-fits-all model but as a platform for dialogue - a heuristic to think and talk with - in collective reflections between researchers and potential partners in establishing relations in the initial phase of collaborative research. More specif-

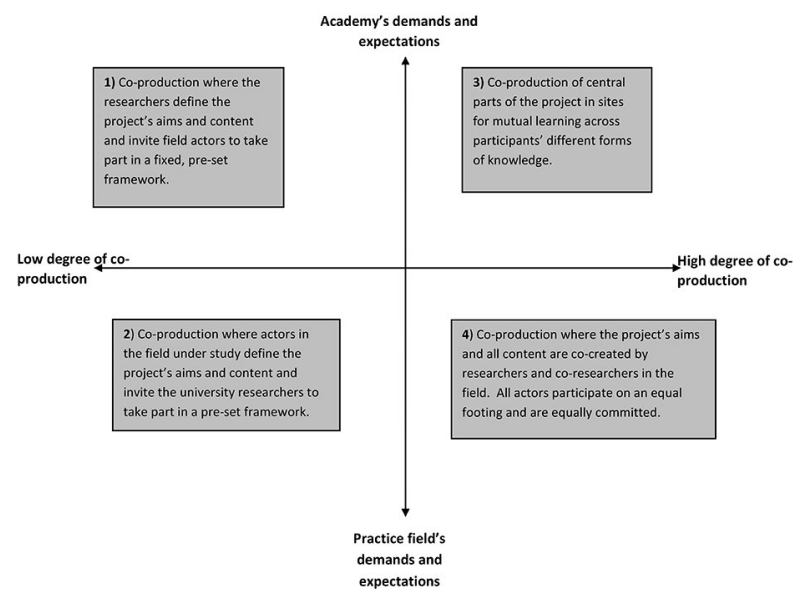

Figure 1. Ideal typical positions in collaborative research relations. 
ically, we suggest that it can be used as a platform for critical, reflexive discussion between researchers and potential partners/co-researchers of the meanings they ascribe to collaboration and dialogue - and the implications of those meanings for expectations with respect to the types and degrees of participation in the research process and with respect to results. In applying the typology as a platform for dialogue in other research projects, different researchers and their potential partners may identify more positions or may conceptualise one or more of the positions we identify differently, and this would be perfectly legitimate.

\section{Position 1. Co-production where the researchers define the project's aims and content and invite field actors to take part in a fixed, pre-set framework}

This ideal typical position is often encouraged by funding calls. Although calls do not explicitly state that the definition of project aims and content are solely in the hands of the researchers, they tend to assume a pre-set research design. Such calls stipulate that the description of the proposed collaborative research project delineates all stages of the research process from the formulation of research question and aims to research design and expected results and impact. ${ }^{41}$ No heed is taken of the emergent nature of collaborative research whereby the framework is never fixed in advance but co-created by university researchers and coresearchers in the course of the research process. In addition, power imbalance in the field under study can make participation in the formulation of the research proposal impossible for the potential research partners and co-researchers whose lives the research project is ostensibly designed to improve (in our case, patients with cognitive impairment and their relatives). Thus, funding calls reproduce the voice of the sovereign researcher in which academic knowledge reigns supreme from start to finish. We referred earlier to literature on the challenges of engaging in action research that has originated in applications penned by the university researchers alone ${ }^{42,53}$ and also Gayá Wicks and Reason point out that the beginning of the action research process is crucial for its success or failure. ${ }^{39}$ The further the actors in the field (in our case, patients, relatives and social and health care practitioners) are from being part of the formulation of a collaborative research proposal, the greater the risk that the project does not become a joint project. If the project is not joint, expert knowledge will not be democratized in spaces for co-production and not all participants will have an active stake and a vested interest with respect to the results.

Position 2. Co-production where actors in the field under study define the project's aims and content and invite the university researchers to take part in a pre-set framework

Projects based on this ideal typical position take the form of evaluations, phenomenologically oriented de- scriptions of (best) practice, or experiments to support evidence-based practices. Such projects are often in line with neo-liberal discourse whereby research is construed as a commodity and its usefulness is judged in terms of its capacity to generate innovations that strengthen the market position of the researcher, research team, institution or organisation under study. ${ }^{54,55}$ Phillips et al. ${ }^{2}$ (p. 3) point to how an instrumentalisation of research within the terms of neo-liberal discourse may conflict with views of co-production as processes of mutual learning that are at least as important as the outcome. Moreover, Staunæs and Søndergaard ${ }^{55}$ (p. 8) note how, in their research project, the practice field was infused not only with neoliberal discourse but also realist discourse which underpinned demands for results within the terms of the prevailing, taken-for-granted ways of talking about, understanding and organising the world. Both neoliberal and realist epistemologies clashed with the poststructuralist epistemology of their research which offered reflexivity as a strategy for destabilizing the taken-for-granted and opening up for alternatives (p. 8).

We acknowledge that projects designed solely to meet the expectations and demands of the practice field can give valuable insights for the involved actors in the practice field and the research community. However we would argue, from a post-foundationalist perspective, that there is a tendency to take for granted either the greater truth value and objectivity of research-based expert knowledge - in the case of experiments to support evidence-based practices - or the greater truth-value and authenticity of marginalized voices - in the case of phenomenologicallyoriented descriptions of the everyday experiences of, for example, patients or relatives. As we noted earlier, telling others' stories for them always entails objectification of the other. Thus there is a high risk of uncritically and unreflexively reproducing discourses that instrumentalise knowledge production and maintain the status quo ${ }^{3}$ (p. 274-275).

\section{Position 3. Co-production of central parts of the project in sites for mutual learning across participants' different forms of knowledge}

In this position, the starting-point is that, using dialogue methods, the researchers create spaces in which different participants contribute with different forms of knowledge, and new knowledge is co-produced across those different knowledge forms. Thus expert knowledge is democratized and difference is cultivated: the spaces open up for a polyphonic multiplicity of voices in dialogue across knowledge forms and experiential backgrounds. This position acknowledges that research itself is not the priority for some participants while it is the total occupation of the academic researchers, and it recognises that participants are not equally engaged in all research phases; rather, they contribute and participate in different ways and to different extents depending on their knowl- 
edge interests, knowledge forms and wishes with respect to the results.

This is the ideal typical position on which we assumed our research was based. Our view was that we, as researchers, would not be able to produce relevant knowledge about practice through conventional qualitative research methods such as interviews and observations; all the actors in our narrative were needed for the development of relevant knowledge on the complexity of crossdisciplinary and cross-sectoral collaboration. At the same time, we considered that participants would take part in different ways and to different extents as a function of different knowledges, knowledge interests and wishes with respect to the results.

\section{Position 4. Co-production where the project's aims and all content are co-created by researchers and co-researchers actors in the field. All actors participate on an equal footing and are equally committed}

This position is the most radical. At the same time, it is probably the position many action researchers strive for and/or claim to reach. Here, mutuality is celebrated in all phases of the action research process. This implies that all participants participate on an equal footing and negotiate the framing of all phases - including the analytical process and the communication of results. It underpins the action research criterion of pragmatic validity: that is, that research based on democratising expertise and engaging in the co-production of knowledge not only has the production of new knowledge as a goal but also seeks the mutual learning of all participants through action-oriented inquiry. ${ }^{56}$ Process validity is directed specifically at the extent to which, in the research process itself, problems are defined and addressed collaboratively and the extent to which relations between participants are established and maintained in ways that cultivate the ongoing learning of all participants ${ }^{56}$ (p. 55). The inclusion of multiple voices is treated as a question of ethics, political recognition and empowerment ${ }^{56}$ (p. 56).

We value the democratic ideals expressed in this position but we are also concerned that it may lead to the romanticisation of dialogue and collaboration whereby participation is understood simply as meaning joint or shared action and differences in types and degrees of participation are unacknowledged ${ }^{42}$ (p. 194). Unacknowledged differences may include differences with respect to which voices are dominant and which are excluded or marginalised in the play of knowledge/power in different phases of the project (including the formulation of the research aims, the design of spaces for co-production and the analysis and communication of results). They may also include differences in the extent to which each participant takes part in decision-making in each of the phases. As Cordeiro et al. ${ }^{57}$ (p. 403) point out, [e]ven a democratic collaborative process can be used to maintain structural status quo as many times the so-called democratic processes assume participants have equal conditions to participate.

\section{Our journey}

We suggest that our point of departure was the third position. We wanted to open up for dialogue across multiple forms of knowledge and break down barriers between the potentially involved collaborators in the project. But, at the same time, we recognized that participants (university researchers and co-researchers in the practice field) participate in different ways and to different extents in the project as a function of their prerequisite knowledges, knowledge interests and levels of investment in the results. We did not want, in the terms of Irwin, to do structure in invisible and blurred ways ${ }^{58}$ (p. 171). Instead, our ideal was to facilitate processes which cultivate multiple voices - discourses articulating different forms of knowledge and subjectivities - in order to challenge existing institutional structures. And, at the same time, we would engage in reflexive consideration of the inexorable workings of power/knowledge in the collaborative research process itself whereby certain forms of knowledge and subjectivities would necessarily dominate and others would be marginalised.

While we began in position 3, we shifted to position 4 on the occasions when we implied that we and our potential partners were all in it together and we did not make clear that we were participating to different extents, with different prerequisites and under different conditions. The challenges that we met in the form of time pressure and re-structuring in the field of practice made it difficult to find relevant people in the practice field sufficiently fast. We glided from position 3 towards position 1 as we took on the task of writing the research application and positioned the collaborating partners as informants with a supporting role. This position somewhere between position 3 and position 1 was actualized in the tension in our narrative between the voice of the sovereign researcher who assumes full control of the research process (position 1) and the voice of the democratic researcher who recognizes multiple knowers as experts (positions 3 and 4). When the collaborating partners withdrew their agreement to participate, we reached the end-station of position 1. Here, the voice of the sovereign researcher reigned supreme. We chose to submit the application in the hope of finding new partners who would accept the pre-set research design, were the project, against all odds, to win funding.

Our journey across ideal typical positions for collaborative research relations can be seen as a product of dynamics of inclusion and exclusion taking place in the struggle between different voices. One voice that constructs knowledge production along monologic lines and ascribes full authority to the sovereign researcher (position 1), another voice that constructs parts of the research process as democratic co-production across difference and positions actors 
in the field as co-researchers (position 3) and a third voice that constructs, and sometimes romanticizes, dialogue as a meeting of equals on an equal footing and with equal degrees of involvement and commitment (position 4). These different voices ascribe different meanings to collaboration and dialogue. As Cook asserts, naming is a convention (... ) the sharing of common terminology builds illusionary consensus, i.e. people use the same words to mean different things ${ }^{41}$ (p. 2). In the narrative, it appears as if both we and the potential partners assumed that we were talking within the terms of the same discourse when we referred to collaboration and dialogue. We did not critically reflect on how the different voices articulate different understandings of collaboration and dialogue and, accordingly, different expectations for the nature and extent of joint action. Our frequent articulation of the romantic voice of dialogue - in spite of our espoused commitment to a theorization of dialogue as complex and tensional - masked the privileging of the sovereign researcher voice in the movement towards position 1 which occurred when we failed to establish collaborative relations along the lines of position 3 . We propose the typology as a way of cultivating collaborative relations in the initial phase through providing a platform for dialogue about participants' understandings of collaboration and dialogue and corresponding expectations with respect to the process and results.

\section{References}

1. Reason P, Bradbury H. Handbook of action research. London, UK: Sage; 2008.

2. Phillips L, Kristiansen M, Vehvilâinen M, Gunnarsson E. Knowledge and power in collaborative research: a reflexive approach. London, UK: Routledge; 2013.

3. Edwards R, Brannelly T. Approaches to democratising qualitative research methods. Qual Res 2017;17:271-7.

4. Gallagher KE. The methodological dilemma: creative, critical and collaborative approaches to qualitative research. London, UK: Routledge; 2008.

5. Gershon WL. The collaborative turn: working together in qualitative research. Rotterdam/Boston/Taipei: Sense Publishers; 2009.

6. William P. Public collaboration in public policy and practice: perspectives on boundary spanners. Bristol: The Policy Press; 2012.

7. Aubert A, Soler M. Dialogism: the dialogic turn in the social sciences. In: Kincheloe J, Horn R, eds. The praeger handbook of education and psychology. Westport, CT: Greenwood Press; 2006.

8. Phillips L. The promise of dialogue. The dialogic turn in the production and communication of knowledge. Amsterdam: John Benjamins Publishing Company; 2011.

9. Gomez A, Puigvert L, Flecha R. Critical communicative methodology: informing real social transformation through research. Qual Inquiry 2011;17:235-45.

10. Phillips L. Analysing the dialogic turn in the communication of research-based knowledge: an exploration of the tensions in collaborative research. Pub Understand Sci 2011;20(1): 80-100.
11. Deetz S, Simpson J. Critical organizational dialogue: open formation and the demand of 'otherness'. In: Anderson R, Baxter L, Cissna KN, eds. Dialogue: Theorizing difference in communication studies. Thousand Oaks, CA: Sage; 2004. pp 141-158.

12. Roberts N. Calls for dialogue. In: Roberts N, ed. The transformative power of dialogue. Oxford: Elsevier Science Ltd; 2002. pp 3-24.

13. Tsoukas H. A dialogical approach to the creation of new knowledge in organizations. Org Sci 2009;20:941-57.

14. Fischer F. Democracy and expertise: reorienting policy inquiry. Oxford: Oxford University Press; 2009.

15. Wilsdon J, Willis R. See-through science: why public engagement needs to move upstream. London, UK: Demos; 2004.

16. Dietz T, Stern PC. Public participation in environmental assessment and decision making. Washington, DC: National Academies Press; 2008.

17. Bakhtin MM. The dialogic imagination. Four essays. Austin \& London: University of Texas Press; 1981.

18. Clark K, Holquist M. Mikhail Bakhtin. Cambridge, MA: Harvard University Press; 1984.

19. Morris P. The Bakhtin reader. Bloomsbury: Bloomsbury Academic; 1994.

20. Foucault M. Archaeology of knowledge. London, UK: Routledge; 1972.

21. Foucault M. Discipline and punish: the birth of the prison. Harmondsworth: Penguin; 1977.

22. Foucault M. Truth and power. In: Gordon C, ed. Power/Knowledge selected interviews and other writings 1972-1977. Hemel Hempstead: Harvester Wheatsheaf; 1980.

23. Phillips L, Napan K. What's in the 'co'? Tending the tensions in cocreative inquiry in social work education. Int $\mathrm{J}$ Qual Stud Educ 2016;29:827-44.

24. Olesen BR, Nordentoft HM. Walking the talk? A micro-sociological approach ot the co-production of knowledge and power in action research. Int J Act Res 2013;9:67-95.

25. Nordentoft HM, Olesen BR. A critical reflexive perspective on othering in collaborative knowledge production. Qual Res J [In press].

26. Hong X, Falter MM, Fecho B. Embracing tension: using Bakhtinian theory as a means for data analysis. Qual Stud 2017; 17:20-36.

27. Cooke B, Kothari U. Participation: the new tyranny? London, UK: Zed Books; 2001.

28. Dutta M, Pal M. Dialog theory in marginalized settings: a subaltern studies approach. Comm Theory 2010;20:363-86.

29. Davies S. The rules of engagement: power and interaction in dialogue events. Pub Understand Sci 2013;22:65-79.

30. Delgado A, Kjølberg K, Wickson F. Public engagement coming of age: from theory to practice in STS encounters with nanotechnology. Pub Understand Sci 2011;20:826-45.

31. Kerr A, Cunningham-Burley S, Tutton R. Shifting subject positions: Experts and lay people in public dialogue. Soc Stud Sci 2007;37:385-411.

32. Stirling A. 'Opening up' and 'closing down': power, participation and pluralism in the Social Appraisal of Technology. Sci Technol Human Values 2008;33:262-94.

33. Arieli D, Friedman VJ, Agbaria K. The paradox of participation in action research. Act Res 2009;7:263-90.

34. Cunningham WS. Voices from the field: practitioner reactions to collaborative research initiatives. Act Res 2008;6:373-90. 
35. Kristiansen M, Bloch-Poulsen J. Self-referentiality as a power mechanism, towards dialogic action research. Act Res 2004:2:371-88.

36. Ospina S, Dodge J, Godsoe B, et al. From consent to mutual inquiry: balancing democracy and authority in action research. Act Res 2004;2:47-69.

37. Pedersen $\mathrm{CH}$, Olesen BR. What knowledge - which relations? sharing dilemmas of an action researcher. Int J Act Res2008;4:254-90.

38. Strumińska-Kutra M. Engaged scholarship: steering between the risks of paternalism, opportunism, and paralysis. Organization 2016;23:864-83.

39. Gayá Wicks P, Reason P. Initiating action research: challenges and paradoxes of opening communicative space. Act Res 2009;7:243-62.

40. Kumsa MK, Chambon A, Yan MC, Maiter S. Catching the shimmers of the social: from the limits of reflexivity to methodological creativity. Qual Res 2015;15:419-36.

41. Cook $\mathrm{T}$. Where participatory approaches meet pragmatism in funded (health) research: the challenge of finding meaningful spaces. Forum Qualitative Sozialforschung/Forum: Qual Soc Res 2012;13:1-22.

42. Kristiansen M. Dynamics between organisational change processes and facilitating dissensus in context inquiring dialogues. Int J Act Res 2013;9:1.

43. Frank A. What is dialogical research and why should we do it? Qual Health Res 2005; 15:964-74.

44. Guba E, Lincoln Y. Controversies, contradictions, confluences. In: Denzin NK, Lincoln YS, eds. The landscape of qualitative research: theories and issues. 1. London, UK: Sage; 2008.

45. Baxter L. Voicing relationships. A dialogic perspective. London, UK: Sage; 2011.

46. Hammond S, Anderson R, Cissna K. The problematics of dialogue and power. Communication Yearbook. 27. London, UK: Routledge; 2003.

47. Letiche H. Polyphony and its other. Org Stud 2010;31:26177.

48. Denzin N. Performative ethnography: critical pedagogy and the politics of culture. Thousand Oaks, CA: Sage; 2003.

49. Richardson L. Fields of play: constructing an academic life. 1997.

50. Richardson L, St. Pierre E. Writing: a method of inquiry. In: Denzin NK, Lincoln Y, eds. Collecting and interpreting qualitative materials. London, UK: Sage; 2008.

51. Craig RT. Communication theory as a field. Communication theory 1999;9:119-61.

52. Bacchi C. Why study problematizations? Making politics visible. Open J Pol Sci 2012;2:1-8.

53. Zimmerman Nilsson MH, Wennergren A-C, Sjöberg U. Tensions in communication: teachers and academic facilitators in a critical friendship. Act Res 2016;0:1-18.

54. Nordentoft HM, Olesen BR. Kommunikation i kontekst (Communication in Context). København/CPH: Munksgaards Forlag; 2014.

55. Staunæs D, Søndergaard DM. Who is ready for the results? Reflections on the multi-voicedness of useful research. Int J Qual Stud Educ 2008;21:3-18.

56. Herr K, Anderson G. The action research dissertation: a guide for students and faculty. London, UK: Sage; 2005.

57. Cordeiro L, Baldini Soares C, Rittenmeyer L. Unscrambling method and methodology in action research traditions: theoretical conceptualisations of praxis and emancipation. Qual Res 2017;17:395-407.

58. Irwin K. Into the dark heart of ethnography: the lived ethics and inequality of intimate field relationships. Qual Sociol 2006;29:155-75. 